Provided for non-commercial research and education use. Not for reproduction, distribution or commercial use.

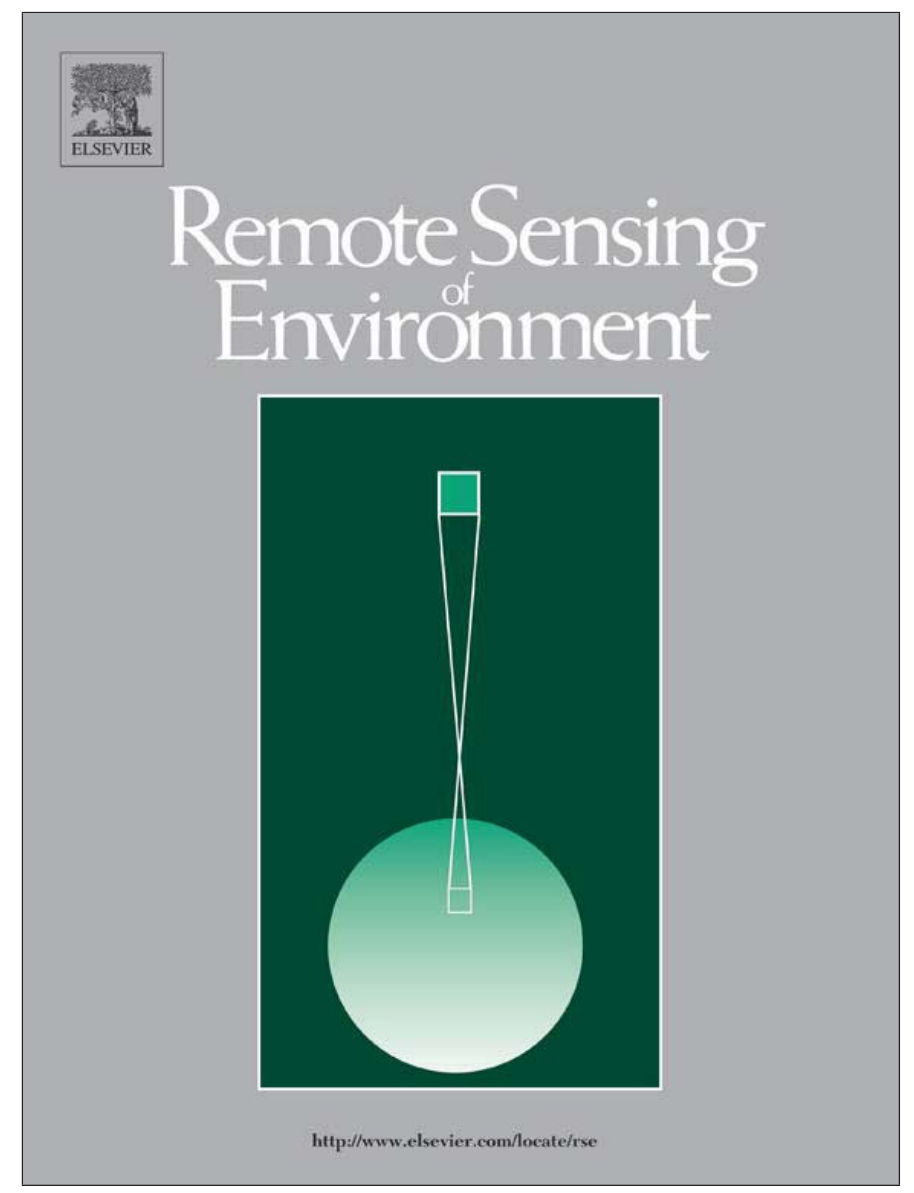

(This is a sample cover image for this issue. The actual cover is not yet available at this time.)

This article appeared in a journal published by Elsevier. The attached copy is furnished to the author for internal non-commercial research and education use, including for instruction at the authors institution and sharing with colleagues.

Other uses, including reproduction and distribution, or selling or licensing copies, or posting to personal, institutional or third party websites are prohibited.

In most cases authors are permitted to post their version of the article (e.g. in Word or Tex form) to their personal website or institutional repository. Authors requiring further information regarding Elsevier's archiving and manuscript policies are encouraged to visit:

http://www.elsevier.com/copyright 


\title{
Spatial and temporal variation in primary productivity (NDVI) of coastal Alaskan tundra: Decreased vegetation growth following earlier snowmelt
}

\author{
John A. Gamon ${ }^{a, b, *}$, K. Fred Huemmrich ${ }^{a, c}$, Robert S. Stone ${ }^{\text {d,e }}$, Craig E. Tweedie ${ }^{f}$ \\ a Desert Research Institute, Reno, NV, USA

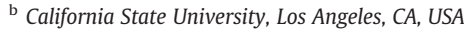 \\ c Joint Center for Earth Systems Technology (JCET), University of Maryland Baltimore County, Code 618, NASA Goddard Space Flight Center, Greenbelt, MD 20771, USA \\ d National Oceanographic and Atmospheric Administration, Earth System Research Laboratory, Global Monitoring Division, Boulder, CO, USA \\ e Cooperative Institute for Research in Environmental Sciences, University of Colorado, Boulder, CO, USA \\ ${ }^{\mathrm{f}}$ Systems Ecology Laboratory, Department of Biology, University of Texas at El Paso, El Paso, TX 79968, USA
}

\section{A R T I C L E I N F O}

\section{Article history:}

Received 10 August 2012

Received in revised form 19 October 2012

Accepted 23 October 2012

Available online $\mathrm{xxxx}$

\section{Keywords:}

Growing season length

Snowmelt

Arctic tundra productivity

Drought

NDVI

Spectral reflectance

Remote sensing

Temperature

\begin{abstract}
A B S T R A C T
In the Arctic, earlier snowmelt and longer growing seasons due to warming have been hypothesized to increase vegetation productivity. Using the Normalized Difference Vegetation Index (NDVI) from both field and satellite measurements as an indicator of vegetation phenology and productivity, we monitored spatial and temporal patterns of vegetation growth for a coastal wet sedge tundra site near Barrow, Alaska over three growing seasons (2000-2002). Contrary to expectation, earlier snowmelt did not lead to increased productivity. Instead, productivity was associated primarily with precipitation and soil moisture, and secondarily with growing degree days, which, during this period, led to reduced growth in years with earlier snowmelt. Additional moisture effects on productivity and species distribution, operating over a longer time scale, were evident in spatial NDVI patterns associated with microtopography. Lower, wetter regions dominated by graminoids were more productive than higher, drier locations having a higher percentage of lichens and mosses, despite the earlier snowmelt at the more elevated sites. These results call into question the oft-stated hypothesis that earlier arctic growing seasons will lead to greater vegetation productivity. Rather, they agree with an emerging body of evidence from recent field studies indicating that early-season, local environmental conditions, notably moisture and temperature, are primary factors determining arctic vegetation productivity. For this coastal arctic site, early growing season conditions are strongly influenced by microtopography, hydrology, and regional sea ice dynamics, and may not be easily predicted from snowmelt date or seasonal average air temperatures alone. Our comparison of field to satellite NDVI also highlights the value of in-situ monitoring of actual vegetation responses using field optical sampling to obtain detailed information on surface conditions not possible from satellite observations alone.
\end{abstract}

(C) 2012 Elsevier Inc. All rights reserved.

\section{Introduction}

Global circulation models predict that current atmospheric forcing will lead to significant warming of the terrestrial surface in the next few decades, with the most rapid warming expected in northern latitudes (ACIA, 2005; IPCC, 2007). Long-term temperature trends confirm this geographic pattern of warming: the North Slope of Alaska has warmed rapidly, with an increase of approximately $2-3{ }^{\circ} \mathrm{C}$ reported for northern Alaska, over recent decades (Chapin et al., 2005; Hinzman et al., 2005; Overland et al., 2002). One possible consequence of northlatitude warming is a longer growing season, coupled with enhanced greening and productivity of northern latitudes. Indeed, satellite observations (Bhatt et al., 2010; Goetz et al., 2005; Myneni et al.,

\footnotetext{
* Corresponding author at: Depts. of Earth \& Atmospheric Sciences and Biological Sciences, University of Alberta, Edmonton, Alberta, Canada. Tel.: + 1780492 0345; fax: +17804922707 .

E-mail address: gamon@ualberta.ca (J.A. Gamon).
}

1997) suggest that earlier growing season and enhanced greening are already occurring in many arctic regions, although independent field confirmation of satellite observations has been largely lacking, with the exception of Bhatt et al. (2010). Historical records of vegetation in Alaska's North Slope provide additional evidence of enhanced north-latitude greening in the form of increased vegetation growth (Bhatt et al., 2010; Chapin et al., 2005; Sturm et al., 2001). Because warming has been particularly rapid in Alaska (Chapin et al., 2005; Hinzman et al., 2005), regime changes in this region may be indicative of how other northern terrestrial ecosystems will change in response to similar forcing mechanisms.

Of particular interest and concern is the response of arctic landscapes to altered climate and the potential for shifting biosphere-climate feedbacks. It is generally assumed that warming of northern latitudes will enhance photosynthetic productivity (hypothesis \#1), and the reported increased greening and vegetation cover in northern latitudes (Bhatt et al., 2010; Goetz et al., 2005; Myneni et al., 1997; Sturm et al., 2001) provides evidence for enhanced productivity. However, experimental 
studies and direct measurements of gas exchange or carbon balance in recent decades suggest that tundra ecosystems can be net sources of carbon to the atmosphere, due to enhanced ecosystem respiration with warming (hypothesis \#2, Oechel et al., 1993; Mack et al., 2004; Schuur et al., 2008). Clearly, both photosynthetic and respiratory processes can be stimulated by warming (Oberbauer et al., 2007), and the balance of these processes determines the net carbon flux (Huemmrich et al., 2010a,b; Jahn et al., 2010). Despite many local observations of enhanced photosynthesis and respiration with increasing temperature, we know little about how the net biosphere-atmosphere carbon balance may be changing for the Arctic as a whole, primarily because of the vast areas and different vegetation types involved, most of which are relatively inaccessible. This sampling challenge suggests that remote sensing can play a key role in resolving the carbon balance. However, to be effective, retrievals from remote sensing must be validated using field observations that are well-grounded in a solid ecophysiological understanding of the basic ecosystem processes affecting the carbon balance. We demonstrate that field optical sampling (proximal remote sensing) can play an important role in this validation.

Multi-factor studies of climate change effects on terrestrial ecosystems demonstrate that carbon balance cannot always be predicted by changes in temperature alone, but is determined by a complex interplay of many factors, all of which may be changing simultaneously (Field et al., 1992; Mooney et al., 1991). Likely factors include moisture availability, nutrient availability, species composition, and atmospheric carbon dioxide levels, all of which interact with temperature. The productivity and carbon balance of arctic vegetation are known to be particularly responsive to moisture (Bliss et al., 1984; Chapin et al., 1995; Oechel et al., 1993) and nutrients (Shaver et al., 2001), both of which can vary over short distances and time scales and are likely to change with climate. Small-scale variations in factors that determine productivity and composition make it difficult to use coarse-scale satellite data to understand or quantify arctic vegetation changes in response to regional climate variation.

Temperature and moisture are key variables determining the carbon balance of arctic tundra (Huemmrich et al., 2010a,b; Jahn et al., 2010). Tundra ecosystems are particularly sensitive to prevailing moisture conditions, because production is often moisture-limited in tundra ecosystems (Bliss et al., 1984; Huemmrich et al., 2010 a,b).

For arctic tundra, photosynthesis, respiration, and production tend to increase with moisture, but these patterns can reverse when the surface becomes fully inundated (Dagg \& Lafleur, 2011). Both respiration and photosynthesis are also strongly temperature-dependent, but exhibit different temperature optima that vary with species and growth conditions (Berry \& Björkman, 1981; Field et al., 1992). In northern ecosystems, temperature and moisture are often linked. For example, recent warming has been accompanied by increasing summer thaw depth, which often results in localized draining and drying of surface soils (Jorgenson et al., 2006; Smith et al., 2005). Further complicating the prediction of carbon balance is the fact that ecosystem respiration is composed not only of the respiration of recently-fixed carbon (i.e. autotrophic respiration from vegetation), but also involves heterotrophic respiration of ancient carbon deposits in deeper tundra layers (Jahn et al., 2010; Schuur et al., 2008).

While many studies suggest that northern warming will enhance vegetation productivity and carbon uptake by arctic ecosystems (e.g. Goetz et al., 2005; Groendahl et al., 2007; Myneni et al., 1997), an alternate consideration is that earlier snowmelt in northern latitudes associated with a warming climate may lead to drier growing seasons, resulting in reduced photosynthetic carbon uptake. In recent years, large regions of the Arctic have undergone surface hydrological changes resulting from a warmer, deeper active layer (Smith et al., 2005). Tundra in the North Slope of Alaska may be undergoing a regime change towards drier conditions (Mack et al., 2011). In Barrow, recent studies have reported vegetation cover changes consistent with surface drying and reduced summer net primary production (Lara et al., 2012; Lin et al., 2012). These recent observations, combined with a history of reports documenting drought limitations to photosynthesis and productivity in arctic vegetation (Bliss et al., 1984; Huemmrich et al., 2010a\&b; Oechel et al., 1993), suggest that drought restraints could override any warming benefits to vegetation growth. Mosses, which account for a large fraction of arctic vegetation cover, are particularly sensitive to such drying and rapidly shut down photosynthesis during dry periods (McNeil \& Waddington, 2003; Silvola, 1990). Thus, it is particularly likely that tundra productivity and carbon balance would be strongly influenced by the particular combination of temperature and moisture experienced during the short growing season.

A challenge to understanding northern latitude ecosystem responses to rapid climate change has been the lack of sustained observations of ecosystem processes. There is a strong need for consistent, repeatable sampling of ecosystem properties and processes across the Arctic. The satellite record offers some promise, but also presents several technical difficulties that are particularly profound in northern latitude sampling. These challenges include persistent cloud cover, low sun angles, errors arising from temporal compositing methods, the lack of standard band definitions, the poor resolution of fine-scale surface features due to large pixel sizes, and the confounding effects of water (variably present as liquid water, snow, or ice, each with its own characteristic optical properties) (Stow et al., 2004). All of these factors complicate the characterization of surface properties, and can lead to ambiguous conclusions regarding changes in vegetation cover and physiological activity for arctic regions. For example, satellite detection of apparent surface "greening" attributed to vegetation growth can be caused by a reduction in snow cover (associated with an earlier snowmelt) or by a reduction in the area of standing water (associated with increasing thaw depth). Given the strong role remote sensing has played, and is likely to play, in understanding biotic responses to climate change, and given the technical challenges described above, there is a particular need for field-based optical measurements of the tundra surface that can independently validate satellite observations. Because weather and climate may have different local effects depending upon microclimate, the ability to distinguish microtopographic effects on surface conditions at a high temporal resolution may be particularly useful in revealing underlying functional processes contributing to ecosystem change.

To meet the need for repeatable, accurate surface measurements that characterize biospheric responses, we implemented a field sampling protocol for surface reflectance involving repeated transect sampling with a field spectrometer. The fine spatial, temporal, and spectral scales of this sampling allowed detailed observations of the response of tundra productivity to seasonal and interannual changes in weather conditions as a proxy for changing climate. By sampling at the surface-atmosphere interface (under the atmosphere rather than through the atmosphere), we were able to avoid the confounding effects of cloud cover that often leads to ambiguous retrievals of surface reflectance. This sampling method was implemented over three successive growing seasons to reveal the detailed response of an arctic tundra ecosystem to a variety of factors (microtopography, species composition, temperature, and moisture).

The primary goals of this study were to better quantify the spatial and temporal dynamics of tundra productivity in response to changing temperature and moisture regimes, and to test the hypothesis that an earlier growing season leads to greater vegetation productivity. In this case, NDVI (an optical index of vegetation greenness), was used as a proxy for productivity based on observations of significant correlations between NDVI, above-ground biomass, and leaf area index for nearby tundra vegetation (Goswami, 2011).

\section{Methods}

All field optical measurements were conducted along a 100-m transect (center lat-lon coordinates: 71.32202265 and -156.60297), located approximately 300 m southeast of the National Oceanic and Atmospheric 
Administration (NOAA) Earth System Research Laboratory (ESRL) Global Monitoring Division (GMD) baseline observatory near Barrow, AK (BRW). Our research site is included in the SpecNet network (Spectral Network Gamon et al., 2006b, 2010). The dominant vegetation of this area is wet sedge tundra, typical of coastal arctic, containing "patterned ground" with characteristic troughs and high-centered polygons, a landscape pattern common near Barrow, Alaska (Brown et al., 1980). Dominant species, determined by sampling meter-square plots along the transect in August 2001, are listed in Table 1.

\subsection{Meteorological data}

Daily average broadband solar irradiance was measured at the adjacent NOAA GMD (BRW) site. Air temperature at a height of $2 \mathrm{~m}$ was also measured at BRW and expressed as daily averages. Precipitation data were measured at the National Weather Service's (NWS) Barrow station, and were obtained from http://www.climate.gov/\#dataServices, and expressed as daily totals of water-equivalent precipitation. To help visualize inter-annual differences, temperature was also expressed as growing degree days (cumulative values above $0{ }^{\circ} \mathrm{C}$ ), and precipitation was also expressed as cumulative totals, using day 131 as a starting date.

\subsection{Soil moisture}

Soil moisture was sampled at the "Barrow 1" site (Soil Survey Staff, Natural Resources Conservation Service, United States Department of Agriculture, Soil Climate Research Station Data, accessed May 24, 2012, from http://soils.usda.gov/survey/smst/). The sampling location (71.32238923, - 156.6107969 W) was approximately $250 \mathrm{~m}$ from the optical sampling transect on a similar landscape and elevation. Soil moisture was sampled at 3 depths $(5,20$, and $30 \mathrm{~cm})$ with 4 replicates during the study period (2000-2002) using 12 dielectric constant soil moisture/temperature sensors (Hydra Probe, Stevens Vitel, Inc., Chantilly, VA, USA) attached to dataloggers (Campbell Scientific, Logan, UT, USA). Data from the 12 sensors were averaged to create a single average soil moisture value, expressed as a unitless volumetric fraction of water ( $\mathrm{vfw}$ ), with units of $\mathrm{m}^{3}$ water per $\mathrm{m}^{3}$ soil. Note that since the dielectric constant of water increases as water thaws, and is also responsive to liquid soil water content (Hydra Soil Moisture Probe User's Manual, 1994, Stevens Vitel, Inc., Chantilly VA, USA), this

Table 1

Common species and genera found along the sampling transect by category (lichen, moss, and vascular plant).

\begin{tabular}{lll}
\hline Mosses & Lichens & Vascular plants \\
\hline Aulacomnium turgidum & Alectoria nigricans & Graminoids \\
Dicranum elongatum & Cetraria cucullata & Arctagrostis latifolia \\
Drepanocladus revolvens & Cetraria nivalis & Carex aquatilis \\
Drepanocladus uncinatus & Cladina rangiferina & Dupontia fisherii \\
Polytrichum sp. & Cladonia chlorophaea & Eriophorum angustifolium \\
Sphagnum sp. & Cladonia scabriuscula & Eriophorum scheuzerii \\
& Cladonia squamosa & Eriophorum vaginatum \\
& Dactylina arctica & Luzula confusa \\
& Ochrolechia frigida & Poa arctica \\
& Pertusaria sp. & Dwarf-shrubs \\
& Sphaerophorus globosus & Salix pulchra \\
& Thamnolia subuliformis & Salix rotundifolia \\
& & Saxifraga spp. \\
& & Vaccinium vitis-idaea \\
& & Cochlearia officinalis \\
& & Forbs \\
& & Potentilla hyparctica \\
& & Ranunculus nivalis \\
& Senecio atropurpureus \\
& Stellaria edwardsii \\
& Petasites frigidus \\
& Papaver macounii \\
\hline
\end{tabular}

method provides an estimate of soil water available to plants during the early growing season.

\subsection{Spectral reflectance}

Spectral reflectance measurements were made at each meter along a 100-meter transect running east-west across the landscape (center lat-lon coordinates were 71.32202265 and -156.60297 , respectively). In most cases, reflectance measurements employed a portable field spectrometer with two detectors (UniSpec DC, PP Systems, Amesbury MA), one sampling surface radiance, and the other sampling sky irradiance. These two signals were compared over a white reference standard (Spectralon, LabSphere, North Sutton, New Hampshire, USA), yielding a cross-calibration used to calculate reflectance (see Gamon et al., 2006a for details). By simultaneously correcting each surface radiance measurement by the prevailing irradiance, this dual-detector spectrometer corrected for changing light conditions due to the frequent cloud cover in this region. Most days during the sampling period were partly cloudy or fully overcast, rendering optical satellite observation difficult (see below). When the dual-detector spectrometer was not available, reflectance was sampled by a single-detector spectrometer (UniSpec, PP Systems, Amesbury MA), and reflectance calculated by dividing the surface radiance against the radiance of the same white reference standard. For the spectral regions reported here, reflectance measurements from the two instruments were statistically indistinguishable on the basis of a Student's t-test. Consequently, single-detector spectrometer measurements were substituted for those of the dual-detector spectrometer when the dual-detector was not available.

To improve sampling precision, and to enable point-by-point seasonal comparisons within a given year, most measurements during the growing season were conducted by mounting the dualdetector spectrometer on a "tram system" consisting of a mobile cart on a track mounted on a series of tripods raised above the tundra surface (Gamon et al., 2006a; Goswami et al., 2011). In this configuration, the downward-looking foreoptic was mounted on a boom positioned approximately $2.5 \mathrm{~m}$ above the tundra surface. At this range, each spectral reflectance measurement sampled a surface area approximately $0.8 \mathrm{~m}$ in diameter. Sampling from the tram was not always possible, in part because local safety concerns required that the tram tracks be removed for the winter and reinstalled at the start of the next season. To gather data prior to snowmelt and tram deployment each season, measurements were made in the identical tram positions using a manual sampling method that replicated the tram sampling positions using permanent wooden markers and a 100-meter sampling tape. To do this, we walked the transect taking a sample at each meter mark, using a leveled, hand-held mast and boom that replicated the tram sampling position. In 2000 and 2001, the tram was installed just around the time of spring snowmelt and removed at the end of the growing season, thus avoiding snowdrifts that would have led to artifacts in the snowmelt date. In 2002, the entire sampling was conducted manually because the tram system was not available during that year. Transect reflectance measurements were sampled 2-3 times a week during each growing season.

Reflectance spectra were interpolated to yield reflectance for 1-nm wavelength intervals ("bands") between 400 and $1100 \mathrm{~nm}$. The Normalized Difference Vegetation Index (NDVI), a widely used measure of arctic vegetation greenness and productivity (Stow et al., 2004), was then calculated from these interpolated spectra using the following formula:

$\mathrm{NDVI}=\left(\rho_{\mathrm{NIR}}-\rho_{\mathrm{RED}}\right) /\left(\rho_{\mathrm{NIR}}+\rho_{\mathrm{RED}}\right)$

where $\rho_{\text {NIR }}$ and $\rho_{\text {RED }}$ indicate reflectance in the near-infrared (NIR) and red bands, respectively. In this study, we used $670 \mathrm{~nm}$ for the red band, and 800 for the NIR band. Because NDVI measurements were 
nondestructive, they allowed continuous sampling of the same regions during the growing season. Note that some reports (e.g. Hope et al., 1993) have reported variable NDVI-biomass relationships for different arctic vegetation types, so we examined this issue for vegetation of our site. Calibration data collected from a nearby site confirmed a strong correlation between NDVI and above-ground, biomass for several common study species $\left(R^{2}=0.83\right.$ for dominant sedges and $R^{2}=0.78$ for all species combined), confirming the use of NDVI as a useful proxy of above-ground vegetation productivity for this ecosystem, particularly when vegetation composition was not markedly changing, as was the case during this study. Harvest results and NDVI calibrations have been reported elsewhere (Goswami, 2011) so they are not presented in further detail here.

NDVI was calculated for each meter mark along the transect. In some cases, these 100 samples for each date were averaged to create a single mean value for the transect on a given sampling date. These transect-averaged values, also termed "big-pixel" values for their potential to represent a single pixel for a low-resolution satellite sensor, were used to more clearly depict seasonal and year-to-year trends for the site as a whole. To examine spatial and temporal trends at a finer resolution and enable tests of statistical significance, we also calculated NDVI data from each of the (approx. 0.8 m diameter) 100 sampling locations, termed "small-pixel values."

We also measured reflectance at 51 plots, each about $15 \mathrm{~cm}$ in diameter, representing nearly pure areas of representative tundra species. These plots were located within $15 \mathrm{~m}$ of the transect and were measured multiple times in 2001 to describe seasonal changes for representative species from each major cover type (Table 1 ).

\subsection{MODIS NDVI data}

NASA MODIS TERRA NDVI data (MOD13Q1, subsetted land products, collection 5) were obtained from the Oak Ridge National Laboratory Distributed Active Archive Center (ORNL DAAC, Oak Ridge, Tennessee, USA) available at http://daac.ornl.gov/MODIS/modis.html (accessed July 8, 2012). NDVI data were downloaded as a single, 250-m pixel matching the location of the optical sampling transect (71.32202265, - 156.60297), and data were sorted by quality flag values into "good data" (reliability 0 ) and other quality categories (reliability 1-3) for comparison with ground NDVI. Single-pixel NDVI values were selected to minimize possible contamination from standing water, roads, and buildings in nearby pixels.

\subsection{Snowmelt dates}

Snowmelt was determined from surface reflectance and is reported two ways. NDVI values were very sensitive to snow cover, and were compared to field observations of snow cover to evaluate the start and stop of snowmelt along the transect. The start of snowmelt, when some bare ground became visible, was defined as the date when the NDVI first became positive. The end of snowmelt (i.e. snow-free surface, based on field observations) was defined as the date when NDVI reached 0.3. We also used the NOAA GMD BRW snowmelt dates, measured approximately $300 \mathrm{~m}$ from the tram transect. BRW snowmelt was determined as the day of year when the average broadband albedo dropped below a threshold value of 0.3 (Stone et al., 2002).

\section{Results}

\subsection{Meteorological patterns}

Downwelling solar irradiance followed a similar cycle in each of the three years, increasing towards summer solstice, then declining (Fig. 1A). Clearly noticeable is a marked increase in day-to-day variation during the summer growing season (roughly days 150-270) due to increased cloudiness following snowmelt. Cloud cover at Barrow tends to increase during the transition from spring to summer as the snow and sea ice in the adjacent Beaufort Sea melts and releases moisture into the atmosphere. Arctic stratus clouds form and are most common during late summer, when sea ice is at its minimum (Stone et al., 1996). Despite considerable intra-annual variation due to cloud cover (Stone, 1997), differences in cumulative irradiance (Fig. 1B) or average irradiance (Table 2) during the greenup period (DOY 131-220) between years were not significant.

Air temperature trends followed similar patterns in 2000 and 2001, increasing steadily towards day 160 (June) then hovering between 0 and $10{ }^{\circ} \mathrm{C}$ for most of the summer (Fig. 2A). In 2002, air temperature was unusually warm early in the season (days 130-150), leading to an early snowmelt (days 141-157 along the transect; Table 2) then was slightly cooler for most of the subsequent months (days 160-190) than the previous two years (Fig. 2A). Transect snowmelt dates fell within the range of values obtained from the nearby BRW station (300 m away), and had the same rank order, with each year having an earlier melt than the previous year (Table 2).

These temperature patterns can best be seen when plotted as "growing degree days" (summed daily mean values above $0{ }^{\circ} \mathrm{C}$ ) (Fig. 2B). Interestingly, after an initial rapid spring increase, growing degree days for 2002 lagged behind that of the previous two years for much of the growing season, and this delay was particularly evident during days 170-195 (Fig. 2B). From days 195 to 240, covering the peak of the growing season, growing degree days were similar in 2001 and 2002, and both lagged the values for 2000 (Fig. 2B).

Growing season precipitation was generally low, and the pattern and amount of precipitation varied among years, with the greenup period of 2000 having the highest precipitation, and that of 2002 the lowest (Table 2). In 2002, precipitation was low during the first half of the growing season (particularly between days 180 to 220 , Fig. 3A). The lower early-season precipitation in 2002 was more

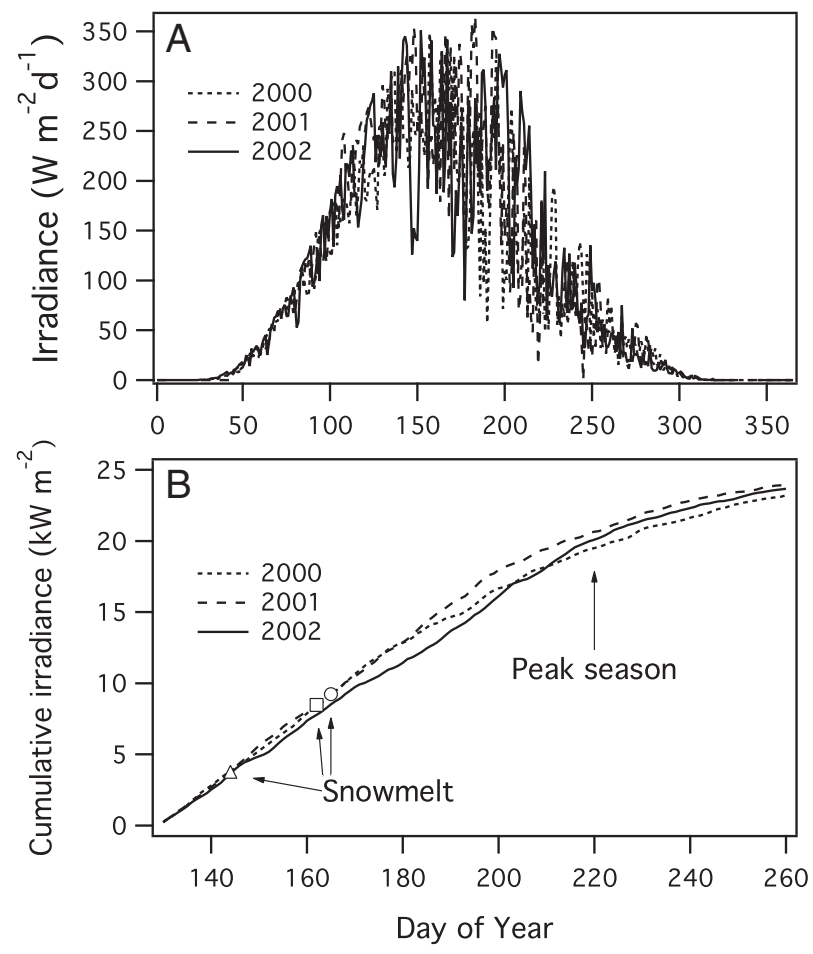

Fig. 1. Daily average downwelling solar irradiance for 2000-2002 for the entire year (top) and cumulative irradiance for the active growing season (bottom). Symbols in panel B indicate NOAA snowmelt dates (see Table 2) for each year. Peak season was determined by maximum NDVI (approximately day 220). 
Table 2

Snowmelt date, meteorological variables, and NDVI in 2000-2002. Snowmelt dates were determined from the study transect and from the nearby NOAA GMD BRW station (see Methods). Average daily irradiance, average daily temperature, average daily precipitation, total precipitation, and volumetric soil water content (vfw, expressed as $\mathrm{m}^{3}$ water per $\mathrm{m}^{3}$ soil) are shown during the greenup phase (DOY 131-220). Growing degree days at peak season (day 220), peak NDVI, and seasonally-integrated NDVI are shown for 2000, 2001, and 2002. Significant differences $(\mathrm{p}<0.05)$ in average meteorological values and peak NDVI values between years are indicated by different superscripts. Seasonally-integrated NDVI was calculated from snowmelt to Julian day 255, using the snow-free NDVI value for this site (0.3) as a baseline.

\begin{tabular}{llll}
\hline & 2000 & 2001 & 2002 \\
\hline Transect snowmelt period (day of year) & $163-168$ & $162-165$ & $141-157$ \\
NOAA snowmelt date $($ day of year) & 165 & 162 & 144 \\
Ave. daily irradiance $\left(\mathrm{Wm}^{-2}\right)$ & $214^{\mathrm{a}}$ & $227^{\mathrm{a}}$ & $221^{\mathrm{a}}$ \\
Ave. daily temperature $\left({ }^{\circ} \mathrm{C}\right)$ & $0.41^{\mathrm{ab}}$ & $-0.69^{\mathrm{b}}$ & $0.76^{\mathrm{a}}$ \\
Growing degree days at peak season & 194 & 142 & 148 \\
Ave. daily precipitation $(\mathrm{mm})$ & $1.06^{\mathrm{a}}$ & $0.77^{\mathrm{a}}$ & $0.44^{\mathrm{b}}$ \\
Total precipitation $(\mathrm{mm})$ & 95 & 70 & 39 \\
Ave. volumetric soil water content $(\mathrm{vfw})$ & $0.189^{\mathrm{a}}$ & $0.184^{\mathrm{a}}$ & $0.179^{\mathrm{a}}$ \\
Peak NDVI & $0.585^{\mathrm{a}}$ & $0.573^{\mathrm{b}}$ & $0.526^{\mathrm{c}}$ \\
Integrated NDVI & 16.7 & 13.4 & 12.2 \\
\hline
\end{tabular}

clearly evident when expressed as cumulative precipitation (Fig. 3B), demonstrating a clear lag by peak season in 2002 relative to the other years.

Following snowmelt, soil moisture closely followed precipitation patterns, particularly between days 180 and 220 leading up to the peak season. In 2000, a large rainfall event on day 187 followed by several smaller events (Fig. $3 \mathrm{~A}$ and $\mathrm{B}$ ) caused a steady increase in both cumulative precipitation and soil moisture towards the peak season (Fig. 3B and C). In 2001, the lack of rain between days 180 and 200 , followed by several rain events between days 200 and 220 , caused a slight decline in soil moisture (days 180-200), followed by an increase to 2000 levels by mid-season (days 200-220, Fig. 3C). In
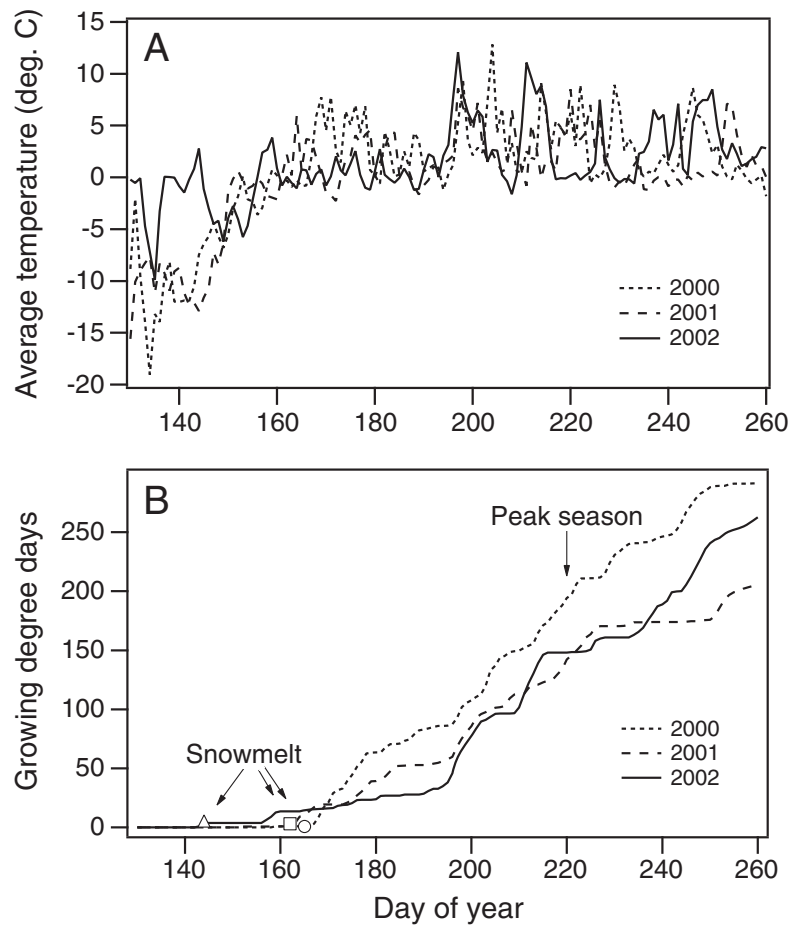

Fig. 2. Daily average temperature (top) or growing degree days (cumulative values above $0{ }^{\circ} \mathrm{C}$, bottom) for $2000-2002$. Symbols in panel B indicate NOAA snowmelt dates (see Table 2 ) for each year. Peak season was determined by maximum NDVI (approximately day 220).
2002, after some initial rain between days 170 and 181, very little additional rain fell in the first half of the growing season, causing both cumulative precipitation and soil moisture to lag behind the values for the previous two years (Fig. 3B and C).

\subsection{Microtopographic effects on surface reflectance}

Spatial and temporal patterns of surface reflectance along the transect revealed clear microtopographic effects on the timing of snowmelt and vegetation growth. A spatial-temporal plot of NDVI from 2001 is shown in Fig. 4. Areas to first emerge from snow (e.g. meters 18 and 65 ) were the local high spots in the landscape. By the peak of the growing season (late July to early August) these high spots that first became snow-free had relatively low NDVI values. By contrast, low-lying regions slow to emerge from snow reached the highest NDVI values by mid-season (e.g. meters 10 and 82 ).
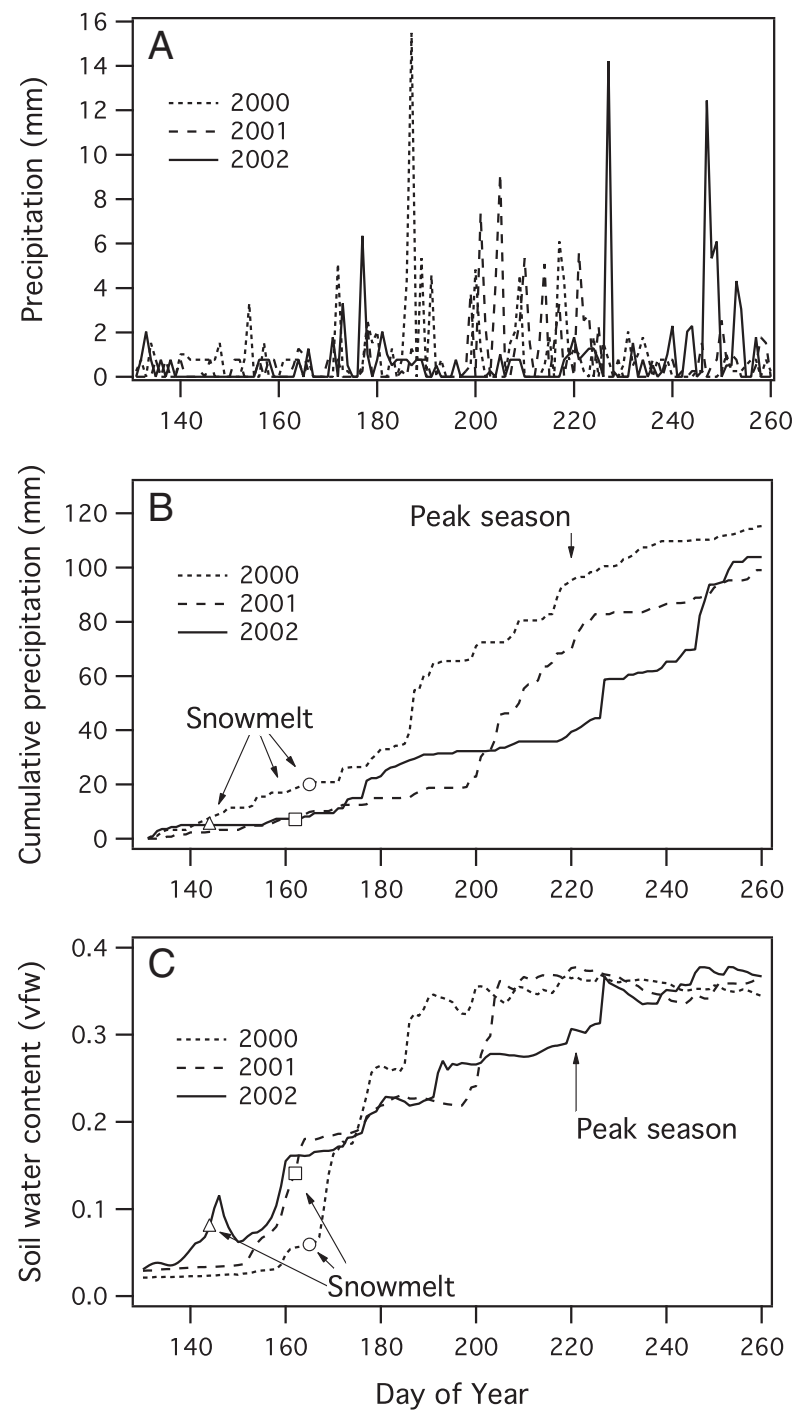

Fig. 3. Daily precipitation totals (A), cumulative precipitation (B), and columnaveraged soil water content expressed as volumetric fraction of water (C) for the 2000-2002 growing seasons. Symbols in panels B and C indicate NOAA snowmelt dates (see Table 2 ) for each year. Peak season was determined by maximum NDVI (approximately day 220). 
These microtopographic effects can be seen more clearly in a "delta NDVI" plot that shows the seasonal increase in NDVI from snowmelt to mid-season (Fig. 5). By referencing mid-season NDVI to the earlyseason, snowmelt value (0.3), this figure removes NDVI artifacts due to snowmelt, and highlights the NDVI changes due to vegetation growth only. The total difference in elevation along the 100-m transect was small $(1 \mathrm{~m})$, with local variations typically much less than this (dashed line, Fig. 5, bottom panel), yet these minor elevation differences had a profound effect on species composition and productivity as indicated by the seasonal increase in NDVI. Slight local depressions (typically $10-20 \mathrm{~cm}$ in depth) tended to have higher moisture content, often containing standing water for short periods. These wet locations were dominated by vascular plants, particularly graminoids (Fig. 5, top panel). These were also the regions with the highest seasonal productivity gains, measured by the mid-season NDVI increase (Fig. 5, bottom panel). By contrast, higher elevation microsites had a greater cover of mosses and lichens, were generally drier, and showed less seasonal change in NDVI (Fig. 5).

\subsection{Seasonal and interannual patterns of surface reflectance}

Comparison of "big-pixel" NDVI values over three successive growing seasons (2000-2002) revealed inter-annual differences in snowmelt, growing season length, and productivity, with each year having an earlier start to the growing season, yet reaching a lower maximum NDVI (Fig. 6). In 2000, complete snowmelt (defined as the date when average NDVI reached the snow-free value of 0.3 ) occurred on day 168, and NDVI peaked at a value of 0.585 (day 217). In 2001, complete snowmelt occurred three days earlier on day 165 , yet the production lagged behind the previous year, with NDVI reaching a maximum value of 0.573 (day 216). This peak value was significantly different from the peak value in 2000 ( $\mathrm{p}=0.002$, paired samples $t$-test). In 2002, complete snowmelt along the transect occurred on day 157 , eleven days earlier than in 2000. At the nearby NOAA site, 2002 was

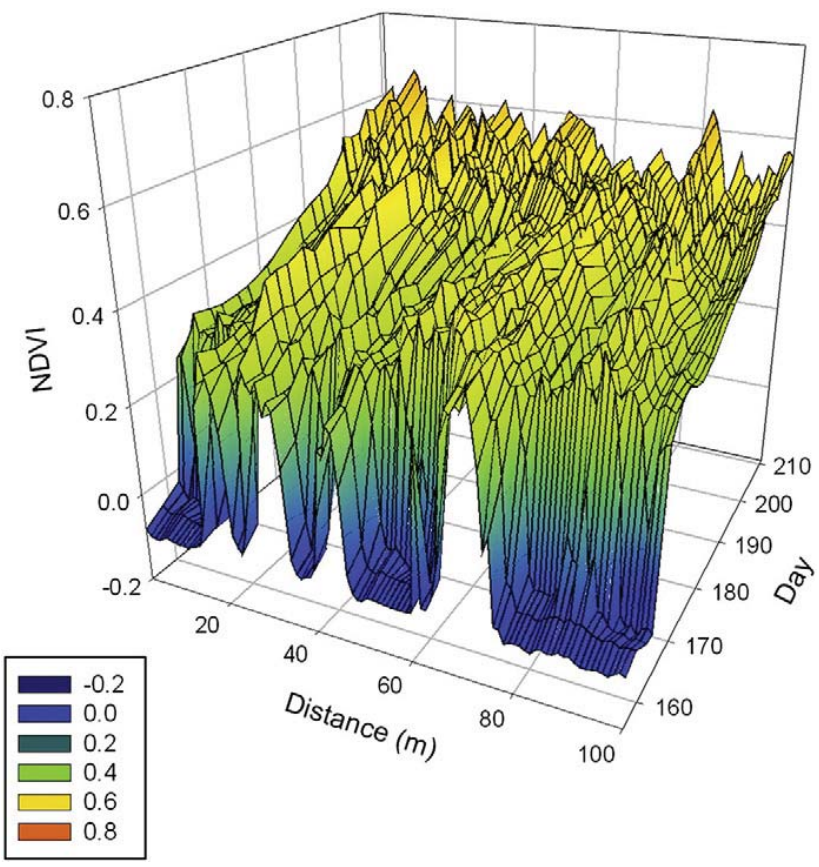

Fig. 4. Spatial and temporal patterns of "small-pixel" NDVI measured along the tram transect in 2001 for the first part of the growing season. Snow-covered values having low NDVI are shown in blue. The rapid rise in NDVI between days 162 and 165 is caused by snowmelt (Table 2), and the more gradual rise following snowmelt is due to vegetation growth. (For interpretation of the references to color in this figure legend, the reader is referred to the web version of this article.)
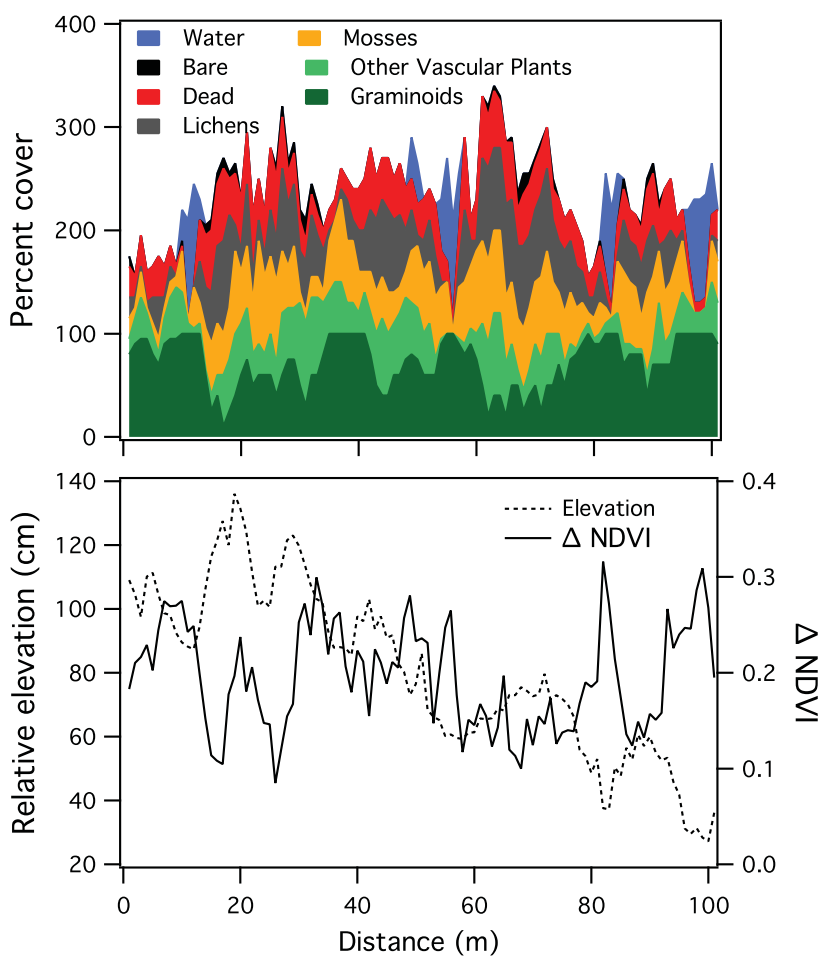

Fig. 5. Vegetation cover (top panel), and seasonal increase in NDVI from snowmelt to mid-season in 2000 ( $\triangle \mathrm{NDVI}$ ) and local elevation (bottom panel) plotted for each meter along the tram transect. Vegetation cover was sampled in early August 2001 and represents the cover at peak-season. Total ground cover exceeds $100 \%$ due to multiple canopy layers (e.g. vascular plants overtopping moss or lichens). $\Delta \mathrm{NDV}$ was determined as the difference between day 220 (maximum NDVI) and day 166 (immediately after snowmelt).

determined to be the earliest snowmelt on record to date (snowmelt records for this site date to the early 1940s, Stone et al., 2005; see also http://www.esrl.noaa.gov/gmd/grad/snomelt.html). Following this remarkably early snowmelt, production lagged behind that measured in the previous two years, with NDVI reaching a maximum NDVI value of only 0.526 (day 222). Despite this unusually early start to the growing season, the peak NDVI value in 2002 was significantly lower than

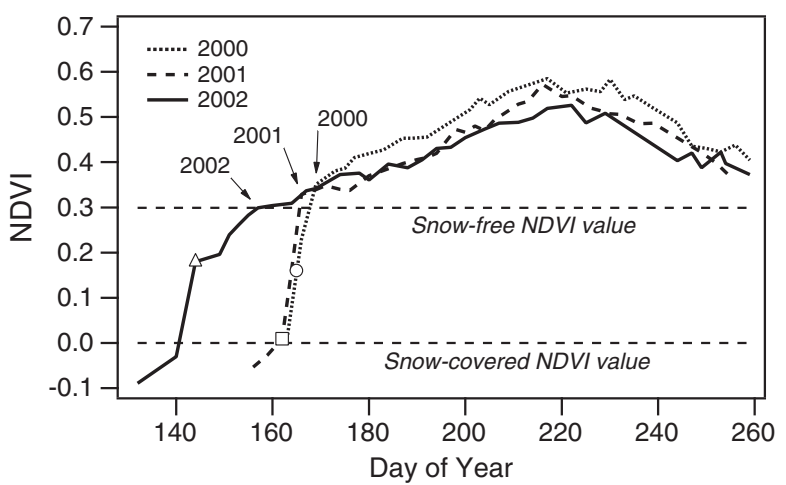

Fig. 6. Seasonal course of the Normalized Difference Vegetation Index (NDVI), an index of "greenness" and plant productivity, during the 2000, 2001, and 2002 growing seasons (samples collected 2-3 times per week). In this case, each "big pixel" NDVI value was calculated from reflectance averaged from the entire transect (100 sampling points). Arrows indicate dates of complete snowmelt along the transect based on visual observation, which coincided with NDVI values exceeding 0.3 . Symbols indicate NOAA snowmelt dates, all of which fell within the transect snowmelt period (NDVI between 0 and 0.3 ). See Table 2 for a summary of snowmelt dates. 
the peak NDVI values in either of the two previous years $(p<0.001$, paired samples $t$-test, Table 2). Integrated NDVI values followed a similar trend, with the lowest integrated NDVI values occurring in 2002 (Table 2).

Reflectance for the three major cover types - mosses, lichens, and vascular plants - revealed contrasting NDVI patterns over the 2001 growing season (Fig. 7). The NDVI for vascular plants closely followed the NDVI for the transect as a whole - increasing towards mid-season (approximately day 220), then declining. On the other hand, moss NDVI initially declined, then gradually increased. This increase followed a period of rainfall starting on day 199 in 2001 (Fig. 3). Lichen NDVI followed a similar decline and increase after the rainfall events. These results reflect the strong sensitivity of physiological activity to moisture, and indicate that the growing-season NDVI patterns at this site are primarily driven by the growth and senescence of the vascular plants.

\subsection{Comparison of ground to satellite NDVI}

MODIS 16-day composite NDVI values were compared to groundmeasured NDVI values from Fig. 6, revealing several key points. In all three years, MODIS NDVI values showed a similar seasonality to ground-based values (Fig. 8). The highest quality MODIS values (solid circles, Fig. 8) tended to be slightly higher than the corresponding ground NDVI values. However, MODIS composite NDVI could not accurately resolve snowmelt, sometimes appearing to lead (Fig. 8A) and other times to lag (Fig. 8B and C) actual snowmelt. Similarly, MODIS was unable to pinpoint the date or maximum value of peak NDVI, sometimes yielding maximum values that were later than (Fig. 8A and B) or earlier than (Fig. 8C) the maximum values measured on the ground.

\section{Discussion}

Our findings contradict the hypothesis predicting greater production under longer growing seasons. We expected earlier spring melt and a longer snow-free growing season to result in greater vegetation growth, as had been suggested for other northern latitude ecosystems (e.g. Bhatt et al., 2010; Goetz et al., 2005; Myneni et al., 1997). Instead, our measurements indicated an unexpected and progressive decline in vegetation growth (sampled as NDVI) as snowmelt advanced each year (Fig. 6), with the lowest midseason NDVI attained in 2002, the year with the earliest snowmelt on record (Stone et al., 2005). Clearly, factors other than the timing of snowmelt determined the overall seasonal productivity during these years at this site.

Reduced production with earlier snowmelt was also apparent in the microtopographic analysis, where sites that emerged earlier

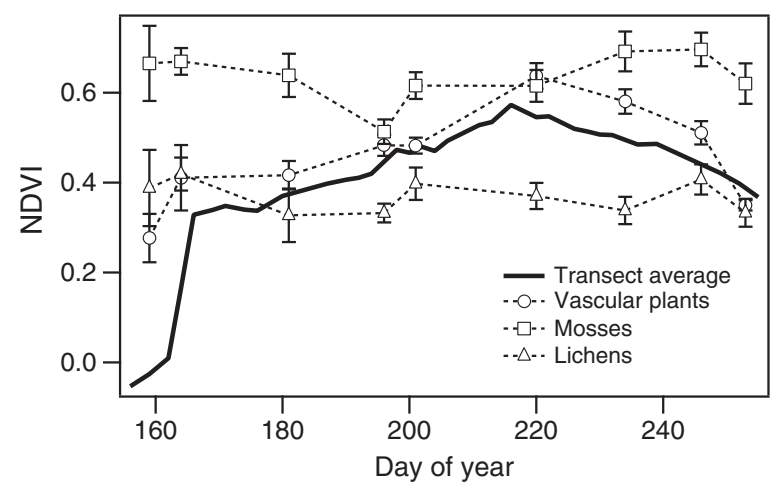

Fig. 7. Seasonal progression of NDVI for three dominant vegetation cover types (vascular plants, mosses and lichens) along the transect in 2001. Also shown for comparison is the average NDVI pattern for the entire transect from Fig. 6.
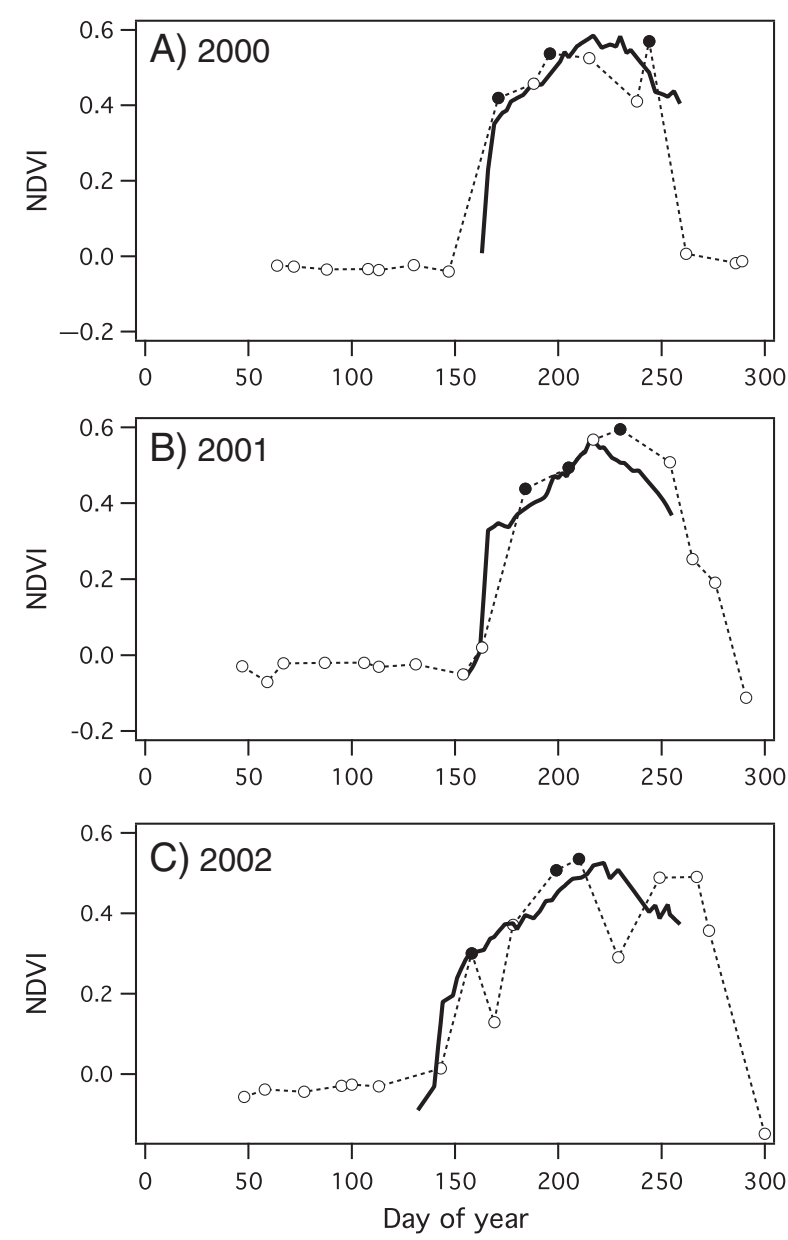

Fig. 8. Comparison of MODIS composite NDVI (circles and dashed lines) to ground-measured NDVI (solid lines) for 2000 (A), 2001 (B) and 2002 (C). Solid circles indicate MODIS NDVI data having the highest quality flag (reliability $=0$ ); open circles indicate points with lower quality flags (reliability $=1,2$ or 3 ). MODIS values were plotted according to actual measurement dates (not nominal composite dates) to facilitate comparison with ground measurements.

were higher and drier, and tended to have less productivity, measured as lower mid-season NDVI values (Figs. 4 and 5). While the mechanisms and time scales of the two responses are different, both are driven by moisture. Reduced NDVI in successive years was caused by reduced vegetation growth due to moisture limitations. On the other hand, the spatial differences in NDVI due to microtopographic variation represent the result of a long-term vegetation response to moisture patterns. These observations, while contrary to simple predictions of enhanced productivity with earlier snowmelt, are actually consistent with ecophysiological studies linking tundra production to moisture and temperature conditions. Our findings most likely reflect water limitations to production at this site, and are consistent with a body of literature that suggests that the productivity of arctic tundra is often moisture-limited (Bliss et al., 1984; Chapin et al., 1995; Huemmrich et al., 2010a,b; Oechel et al., 1993). Other arctic field studies have reported similar findings, suggesting that arctic vegetation productivity is not necessarily correlated with the timing of snowmelt, but with environmental conditions prevailing early in the growing season prior to peak production (Humpreys \& LaFleur, 2011).

Our observations suggest that conditions during the early growing phase, particularly precipitation and soil moisture may be the determining factors, rather than irradiance, temperature or growing 
season length, per se. Of these meteorological variables, precipitation and soil moisture best matched the NDVI patterns (Table 2). Despite earlier snowmelt in each year, productivity (measured as peak NDVI) declined, and this decline closely matched the precipitation and soil moisture patterns during the first half of the growing season (days 131-220). By contrast, NDVI showed no clear association with either solar irradiance or temperature over the same period. Following an unusual early-season warming in 2002, cool temperature anomalies just after snowmelt may have contributed to the particularly low productivity in that year. The combination of drier and cooler conditions in 2002, relative to the previous two years, probably explains the lower NDVI for this year. In this study, water limitation appeared to override the effects of growing season length and warmer initial growing-season temperatures on overall seasonal productivity.

The importance of moisture limitations to productivity can also be seen in the clear relationship between microtopography and NDVI for this site, with locally low and wet areas exhibiting the highest mid-season NDVI peaks. These peaks were clearly linked to vegetation cover, with moisture-loving graminoids (e.g. Carex aquatilis) dominating in these locations. By contrast, the elevated microsites, which were less than $1 \mathrm{~m}$ higher, had a greater percentage of drought-tolerant cover types, including prostrate shrubs, mosses and lichens. Our findings are consistent with other recent reports from this area showing contrasting photosynthetic light-use efficiency and productivity associated with microtopography and moisture (Huemmrich et al., 2010, submitted for publication). Unlike the interannual differences in NDVI that were associated with variation in precipitation and soil moisture, these microtopographic effects represent long-term vegetation community responses to moisture occurring over much longer time spans than the three-year period of this study. Our observations of different vegetation cover types with microsite are consistent with a large body of literature illustrating arctic vegetation community differences with microtopography (Bliss \& Gold, 1994; Brown et al., 1980; Engstrom et al., 2005; Gamon et al., 2012; Webber, 1978).

From these observations, we speculate that regional changes in hydrology reported for many arctic regions (Jorgenson et al., 2006; Smith et al., 2005) could lead to striking changes in surface vegetation, productivity, albedo, and other ecosystem properties, all of which could exert further feedback effects on the climate and atmosphere through changes in surface albedo and carbon balance. These effects would include altered productivity and gas exchange in the short term (Huemmrich et al., 2010b), and altered vegetation patterns in the longer term (Lin et al., 2012; Webber, 1978). Recent studies comparing surface conditions in 2010 to those documented in 1972 provide evidence that some vegetation cover types near Barrow have undergone surface drying and declines in net primary production over that time period (Lara et al., 2012; Lin et al., 2012). Similarly, regional warming and drying recently observed for large regions of the Alaskan North Slope (Mack et al., 2011) could be shifting tundra carbon balance towards carbon release, despite longer growing seasons. These changes, if widespread, could provide a significant positive feedback to a warming climate, and may accelerate and enhance regime changes for Alaska's Slope tundra ecosystems.

Our findings contrast with observations from eddy covariance measurements made at a nearby site that concluded that 2002 was a more productive year than average (Kwon et al., 2006). However, eddy covariance measures net carbon exchange, not gross carbon exchange, and cannot always be partitioned into component photosynthetic and respiratory fluxes. Kwon et al. (2006) did not report gross ecosystem carbon uptake, which would have enabled a more direct comparison with our results. In this coastal tundra, ecosystem respiration can be a large and variable part of the net carbon flux, and the overall balance of carbon uptake and loss is particularly sensitive to soil moisture (Huemmrich et al., 2010b), which undoubtedly varied between years during this study period, leaving it unclear what drove the year-to-year variation in the net carbon flux reported in Kwon et al. (2006). This inability to partition net fluxes into uptake and loss illustrates the difficulty of understanding the driving mechanisms of flux measurements using eddy covariance methods alone, particularly for harsh arctic environments where productivity is low and extreme conditions can easily cause instrument failures leading to data gaps. This also demonstrates the value of independent validation of productivity estimates, and the NDVI sampling method in this study provides one way to do this.

We readily acknowledge that a three-year study is not sufficient to establish definitively the relationships between snowmelt date, temperature, moisture, and seasonal productivity. Furthermore, the location of this particular site near the coast, where weather is strongly influenced by sea-ice patterns, may not be representative of arctic sites in general. However, the moisture limitations to productivity found here corroborate a well-established history of field and experimental observations made over many arctic sites, so the general principles observed here are likely to be widely applicable. Furthermore, vast regions of coastal arctic tundra display similar microtopographic features that affect vegetation distribution and related ecosystem properties and processes (Brown et al., 1980; Gamon et al., 2012), so it is likely that the drought limitations and productivity patterns seen in this particular landscape are of larger significance.

This study was notable in that it included years (2000 and 2001) having "typical" snowmelt date, contrasting with another year (2002) having the earliest snowmelt on record for the period 1941-2011 (Stone et al., 2005; see also http://www.esrl.noaa.gov/gmd/grad/ snomelt.html). The remarkably early snowmelt in 2002 appeared to be associated with regional anomalies in both sea ice and atmospheric circulation as described in Stone et al. (2005), supporting the observation that the regional synoptic conditions and biological responses of Alaska's North Slope are changing, possibly as a result of global warming that has also affected sea ice distributions over the past three decades.

Our observations of a strong rise in NDVI at the time of snowmelt (Figs. 4, 6, and 8) illustrate how earlier snowmelt can masquerade as greater vegetation production when viewed from a satellite. Both snow and standing water are common at this arctic site, and have a strong tendency to lower NDVI values relative to vegetated surfaces. Consequently, decreases in snow or surface water cover can, in themselves, appear as an apparent greening (visible as a rapid rise to a snow-free NDVI value of 0.3 in Figs. 4 and 6). Additionally, the heavy cloud cover of many arctic regions during the growing season (Hope et al., 1999; Narasimhan \& Stow, 2010; see also Fig. 1), makes recovery of accurate surface NDVI values difficult from optical satellites, particularly when using composited data, as demonstrated by our comparison of MODIS NDVI with ground NDVI (Fig. 8). Clearly, composited satellite data cannot accurately depict the rapid NDVI transitions during snowmelt and early-season greening, and this limitation is further confounded by cloud cover. In some cases, use of daily MODIS data (rather than maximum value compositing) can improve the ability to resolve early-season NDVI transitions (Narasimhan \& Stow, 2010). However, without direct evidence of greening from ground measurements or field observations, conclusions of increased arctic vegetation production from satellite measurements should be viewed with caution. Only recently have arctic satellite observations been directly coupled with ground observations (e.g. Bhatt et al., 2010), demonstrating that some (but not necessarily all) NDVI increases are, in fact, associated with enhanced vegetation growth. In our study, direct field observations of the site during the study period confirmed that year-to-year changes in NDVI during the growing season were attributable to differences in productivity and not to differences in cover, standing water, or snow. Further field validation of satellite observations will be needed if we are to reach unequivocal conclusions regarding arctic vegetation change.

Unlike the ground optical measurements, MODIS was not able to clearly resolve interannual differences in snowmelt or NDVI (Fig. 8). 
While the few "high quality" MODIS NDVI values agreed well with field measurements, the majority of the MODIS NDVI values had lower quality values, undoubtedly due to the difficulties of "seeing" the surface due to the frequent cloud cover following snowmelt at this arctic site (Fig. 1A). While it is possible that a more detailed analysis of daily MODIS data could improve the MODIS retrievals (Narasimhan \& Stow, 2010), such an analysis was beyond the scope of this study. The ground optical sampling methods reported here demonstrate the potential of field optical sampling to provide additional insights into the question of the "greening of the arctic" than is possible from satellite or gas flux measurements alone. In situ field reflectance sampling provides frequent, highly repeatable and accurate measurements, avoiding common errors and sampling gaps due to clouds. Field measurement allows long sampling periods, enhancing signal-to-noise over satellite sensors, and this is particularly relevant under limited arctic illumination. This method can readily resolve key events (e.g. snowmelt and rainfall) and microtopographic effects on moisture, species composition, and productivity. To better clarify patterns of arctic vegetation productivity, we propose systematic, automated field sampling of representative arctic locations. Ideally, such sampling would be closely coordinated with other measurements of productivity (e.g. carbon flux and biomass) and confounding variables such as snow cover, standing water, and active layer depth would also be monitored to help interpret signals measured from satellites. The particular advantage of ground sampling is that it can avoid artifacts due to cloud cover, which is a frequent summer feature for many arctic sites. Given the pronounced effect of microtopography on vegetation cover and NDVI, field sampling can also be used to refine our understanding of the variables driving vegetation change or stability at a higher spatial resolution than is possible with the coarser sampling scale of most satellite measurements.

\section{Conclusions}

Contrary to expectation, earlier growing season did not lead to greater greening (NDVI) in this coastal arctic site. These results call into question the simple prediction that an earlier snowmelt or longer growing season will lead to a greener, more productive arctic. For this site, and other regions on Alaska's North Slope, recent surface drying trends could cause reduced vegetation production, despite a trend towards earlier snowmelt. Clearly, conditions during the growing season, rather than growing season length per se, should be considered when evaluating the impact of climate change on arctic vegetation production. Unlike field optical measurements, MODIS satellite NDVI was unable to clearly resolve both the timing of snowmelt and the peak season values. We conclude that reports of the "greening of the arctic" due to enhanced vegetation indices should be taken with caution when based on satellite measurements alone, and that ground optical sampling could provide an independent way to evaluate satellite measurements.

\section{Acknowledgments}

We wish to thank Stan Houston, Erika Anderson, and Jean Van Dalen for assistance in field data collection. Dan Endres and other BRW staff provided helpful discussions and temperature data, David Longenecker and Ellsworth Dutton provided radiation data, Gina Sturm at the National Weather Service's Barrow office provided precipitation data, Cathy Seybold at the United States Department of Agriculture provided technical details of the soil moisture measurements, Suresh-Kumar Santhana-Vannan at ORNL DAAC provided advice on MODIS NDVI products, and the staff of the Barrow Arctic Science Consortium provided field logistical support. We are grateful to the Ukpeagivik Iñupiat Corporation (UIC) for permitting access. Funding for the field component of this study was provided by IARC to J.A. Gamon and K.F. Huemmrich through the Desert Research Institute, Reno, Nevada. Additional support was provided by NASA and
NSF, and final data analysis was supported by NSERC and iCORE/ AITF grants to J.A. Gamon.

\section{References}

ACIA (2005). Impacts of a warming arctic: Arctic climate impact assessment. Cambridge: Cambridge University Press.

Berry, J., \& Björkman, O. (1981). Photosynthetic response and adaptation to temperature in higher plants. Annual Review of Plant Physiology and Plant Molecular Biology, 31, 491-543.

Bhatt, U. S., Walker, D. A., Raynolds, M. K., Comiso, J. C., Epstein, H. E., Jia, G., et al. (2010). Circumpolar Arctic tundra vegetation change is linked to sea ice decline. Earth Interactions, 14(8), 1-20.

Bliss, L. C., \& Gold, W. G. (1994). The patterning of plant communities and edaphic factors along a high arctic coastline - Implication for succession. Canadian Journal of Botany, 72, 1095-1107.

Bliss, L. C., Svoboda, J., \& Bliss, D. I. (1984). Polar deserts, their plant cover and plant-production in the Canadian High Arctic. Holarctic Ecology, 7, 305-324.

Brown, J., Everett, K. R., Webber, P. J., MacLean, S. F., Jr., \& Murray, D. F. (1980). The coastal tundra at Barrow. In J. Brown, P. C. Miller, L. L. Tieszen, \& F. L. Bunnell (Eds.), An arctic ecosystem: The coastal tundra at Barrow, Alaska (pp. 1-29). Stroudsburg, PA: Dowden, Hutchinson \& Ross, Inc.

Chapin, F. S., Shaver, G. R., Giblin, A. E., Nadelhoffer, K. J., \& Laundre, J. A. (1995). Responses of arctic tundra to experimental and observed changes in climate. Ecology, 76, 694-711.

Chapin, F. S., III, Sturm, M., Serreze, M. C., McFadden, J. P., Key, J. R., Lloyd, A. H., et al. (2005). Role of land-surface changes in arctic summer warming. Science, 310 , 657-660. http://dx.doi.org/10.1126/science.1117368.

Dagg, J., \& Lafleur, P. (2011). Vegetation community, foliar nitrogen, and temperature effects on tundra $\mathrm{CO}_{2}$ exchange across a soil moisture gradient. Arctic, Antarctic, and Alpine Research, 43, 189-197.

Engstrom, R., Hope, A., Kwon, H., \& Stow, D. (2005). Spatial distribution of near surface soil moisture and its relationship to microtopography in the Alaskan Arctic coastal plain. Nordic Hydrology, 36(3), 219-234.

Field, C. B., Chapin, F. S., III, Matson, P. A., \& Mooney, H. A. (1992). Responses of terrestrial ecosystems to the changing atmosphere: A resource-based approach. Annual Review of Ecology and Systematics, 23, 201-235.

Gamon, J. A., Cheng, Y., Claudio, H., MacKinney, L., \& Sims, D. (2006). A mobile tram system for systematic sampling ecosystem optical properties. Remote Sensing of Environment, 103, 246-254.

Gamon, J. A., Coburn, C., Flanagan, L. B., Huemmrich, K. F., Kiddle, C., Sanchez-Azofeifa, G. A., et al. (2010). SpecNet revisited: Bridging flux and remote sensing communities. Canadian Journal of Remote Sensing, 36(Suppl. 2), S376-S390.

Gamon, J. A., Kershaw, G. P., Williamson, S., \& Hik, D. (2012). Microtopographic patterns in an arctic Baydjarakh field: Do fine-grain patterns enforce landscape stability? Environmental Research Letters, 7 (015502 (6 pp). Available online at: http://stacks.iop.org/1748-9326/7/015502)

Gamon, J. A., Rahman, A. F., Dungan, J. L., Schildhauer, M., \& Huemmrich, K. F. (2006). Spectral Network (SpecNet): What is it and why do we need it? Remote Sensing of Environment, 103, 227-235.

Goetz, S. J., Bunn, A. G., Fiske, G. J., \& Houghton, R. A. (2005). Satellite-observed photosynthetic trends across boreal North America associated with climate and fire disturbance. PNAS, 102(38), 13521-13525.

Goswami, S. (2011). Monitoring ecosystem dynamics in an arctic tundra landscape using hyperspectral remote sensing and a robotic tram system. Ph.D. Dissertation, University of Texas, El Paso.

Goswami, S., Gamon, J. A., \& Tweedie, C. E. (2011). Surface hydrology of an arctic ecosystem: Multiscale analysis of a flooding and draining experiment using spectral reflectance. Journal of Geophysical Research, 116, G00I07. http://dx.doi.org/10.1029/2010JG001346.

Groendahl, L., Friborg, T., \& Soegaard, H. (2007). Temperature and snow-melt controls on interannual variability in carbon exchange in the high Arctic. Theoretical and Applied Climatology, 88, 111-125.

Hinzman, L. D., Bettez, N. D., Bolton, W. R., Chapin, F. S., Dyurgerov, M. B., Fastie, C. L., et al. (2005). Evidence and implications of recent climate change in northern Alaska and other arctic regions. Climatic Change, 72, 251-298.

Hope, A., Kimball, J., \& Stow, D. (1993). The relationship between tussock tundra spectral reflectance properties and biomass, and vegetation composition. International Journal of Remote Sensing, 14, 1861-1874.

Hope, A. S., Pence, K. R., \& Stow, D. A. (1999). Response of the normalized difference vegetation index to varying cloud conditions in Arctic tundra environments. International Journal of Remote Sensing, 20(1), 207-212.

Huemmrich, K. F., Gamon, J. A., Tweedie, C. E., Oberbauer, S. F., Kinoshita, G., Houston, S., et al. (2010). Remote sensing of tundra gross ecosystem productivity and light use efficiency under varying temperature and moisture conditions. Remote Sensing of Environment, 114(3), 481-489.

Huemmrich, K. F., Kinoshita, G., Gamon, J. A., Houston, S., Kwon, H., \& Oechel, W. C. (2010). Tundra carbon balance under varying temperature and moisture regimes. Journal of Geophysical Research, 115, G00I02. http://dx.doi.org/10.1029/2009JG001237.

Huemmrich, K.F., Gamon, J., Tweedie, C., Campbell, P.K., Landis, D., \& Middleton, E. (submitted for publication). Arctic tundra vegetation functional types based on photosynthetic physiology and optical properties. IEEE Journal of Selected Topics in Applied Earth Observations and Remote Sensing (J-STARS) EO-1 special issue.

Humpreys, E. R., \& LaFleur, P. M. (2011). Does earlier snowmelt lead to greater $\mathrm{CO}_{2}$ sequestration in two low Arctic tundra ecosystems? Geophysical Research Letters, 38, L09703. http://dx.doi.org/10.1029/2011GL047339 (doi: L09703). 
IPCC (2007). Climate change 2007: The physical science basis. Contribution of Working Group I to the fourth assessment report of the Intergovernmental Panel on Climate Change. In S. Solomon, D. Qin, M. Manning, Z. Chen, M. Marquis, K. B. Averyt, M. Tignor, \& H. L. Miller (Eds.), Cambridge, United Kingdom and New York, NY, USA: Cambridge University Press.

Jahn, M., Sachs, T., Mansfeldt, T., \& Overesch, M. (2010). Global climate change and its impacts on the terrestrial Arctic carbon cycle with special regards to ecosystem components and the greenhouse-gas balance. Journal of Plant Nutrition and Soil Science, 173, 627-643.

Jorgenson, M. T., Shur, Y. L., \& Pullman, E. R. (2006). Abrupt increase in permafrost degradation in Arctic Alaska. Geophysical Research Letters, 33, L02503. http: //dx.doi.org/10.1029/2005GL024960.

Kwon, H. -J., Oechel, W. C., Zulueta, R., \& Hastings, S. J. (2006). Effects of climate variability on carbon sequestration among adjacent wet sedge tundra and moist tussock tundra ecosystems. Journal of Geophysical Research, 111, G03014. http: //dx.doi.org/10.1029/2005JG000036.

Lara, M. J., Villarreal, S., Johnson, D. R., Hollister, R. D., Webber, P. J., \& Tweedie, C. E. (2012). Estimated change in tundra ecosystem function from near Barrow, Alaska between 1972 and 2010. Environmental Research Letters, 7(015507). http: //dx.doi.org/10.1088/1748-9326/7/1/015507 (10pp.).

Lin, D. H., Johnson, D. R., Andresen, C., \& Tweedie, C. E. (2012). High spatial resolution decade-time scale land cover change at multiple locations in the Beringian Arctic (1948-2000s). Environmental Research Letters, 7(125502). http://dx.doi.org/10.1088/ 1748-9326/7/2/125502 (14pp.).

Mack, M. C., Bret-Harte, M. S., Hollingsworth, T. N., Jandt, R. R., Schuur, E. A. G., Shaver, G. R., et al. (2011). Carbon loss from an unprecedented Arctic tundra wildfire. Nature, 475, 489-492. http://dx.doi.org/10.1038/nature10283.

Mack, M. C., Schuur, E. A. G., Bret-Harte, M. S., Shaver, G. R., \& Chapin, F. S. (2004). Ecosystem carbon storage in arctic tundra reduced by long-term nutrient fertilization. Nature, 431 440-443.

McNeil, P., \& Waddington, J. M. (2003). Moisture controls on Sphagnum growth and $\mathrm{CO}_{2}$ exchange on a cutover bog. Journal of Applied Ecology, 40, 354-367.

Mooney, H. A., Winnerm, W. E., \& Pell, E. J. (Eds.). (1991). Response of plants to multiple stresses. San Diego: Academic Press.

Myneni, R. B., Keeling, C. D., Tucker, C. J., Asrar, G., \& Nemani, R. R. (1997). Increased plant growth in the northern high latitudes from 1981 to 1991. Nature, 386, 698-702.

Narasimhan, R., \& Stow, D. (2010). Daily MODIS products for analyzing early season vegetation dynamics across the North Slope of Alaska. Remote Sensing of Environment, 114, $1251-1262$.
Oberbauer, S. F., Tweedie, C. E., \& Welker, J. M. (2007). Tundra $\mathrm{CO}_{2}$ fluxes in response to experimental warming across latitudinal and moisture gradients. Ecological Monographs, 77(2), 221-238.

Oechel, W. C., Hastings, S. J., Vourlitis, G., Jenkins, M., Riechers, G., \& Grulke, N. (1993). Recent changes of Arctic tundra ecosystems from a net carbon-dioxide sink to a source. Nature, 361, 520-523.

Overland, J. E., Wang, M., \& Bond, N. A. (2002). Recent temperature changes in the western Arctic during spring. Journal of Climate, 15, 1702-1716.

Schuur, E. A. G., Bockheim, J., Canadell, J. G., Euskirchen, E., Field, C. B., Goryachkin, S. V., et al. (2008). Vulnerability of permafrost carbon to climate change: Implications for the global carbon cycle. Bioscience, 58(8), 701-714.

Shaver, G. R., Bret-Harte, M. S., Jones, M. H., Johnstone, J., Gough, L., Laundre, J., et al. (2001). Species composition interacts with fertilizer to control long-term change in tundra productivity. Ecology, 82, 3163-3181.

Silvola, J. (1990). Combined effects of varying water content and $\mathrm{CO}_{2}$ concentration on photosynthesis in Sphagnum fuscum. Holarctic Ecology, 13, 224-228.

Smith, L. C., Sheng, Y., MacDonald, G. M., \& Hinzman, L. D. (2005). Disappearing Arctic lakes. Science, 308, 1429.

Stone, R. S. (1997). Variations in western Arctic temperatures in response to cloud radiative and synoptic-scale influences. Journal of Geophysical Research, 102, 21769-21776.

Stone, R., Douglas, D., Belchansky, G., \& Drobot, S. (2005). Correlated declines in Pacific Arctic snow and sea ice cover. Arctic Research of the United States, 19, 18-25 (http://www.nsf.gov/pubs/2005/nsf0539/nsf0539_5.pdf)

Stone, R. S., Dutton, E. G., Harris, J. M., \& Longenecker, D. (2002). Earlier spring snowmelt in northern Alaska as an indicator of climate change. Journal of Geophysical Research, 107(D10), 4089. http://dx.doi.org/10.1029/2000JD000286.

Stone, R., Mefford, T., Dutton, E., Longenecker, D., Halter, B., \& Endres, D. (1996). Surface radiation and meteorological measurements: January 1992 to December 1994, Data Rep. ERL-CMDL-11. Boulder, Colorado: National Oceanic and Atmospheric Administration Environmental Research Laboratory.

Stow, D. A., Hope, A., McGuire, D., Verbyla, D., Gamon, J., Huemmrich, F., et al. (2004). Remote sensing of vegetation and land-cover change in Arctic tundra ecosystems. Remote Sensing of Environment, 89, 281-308.

Sturm, M., Racine, C., \& Tape, K. (2001). Increasing shrub abundance in the Arctic. Nature, 411, 546-547.

Webber, P. J. (1978). Spatial and temporal variation of the vegetation and its productivity. In L. L. Tieszen (Ed.), Vegetation and production ecology of an Alaskan Arctic tundra (pp. 37-112). New York, NY: Springer-Verlag. 